Port Acadie

Revue interdisciplinaire en études acadiennes

An Interdisciplinary Review in Acadian Studies

\title{
Patrimoine oral et valorisation à l'ère du numérique : introduction
}

\section{Marlène Belly et André Magord}

Numéro 30, automne 2016

Patrimoine oral et valorisation à l'ère du numérique ( $\left({ }^{\text {ère }}\right.$ partie)

URI : https://id.erudit.org/iderudit/1056917ar

DOI : https://doi.org/10.7202/1056917ar

Aller au sommaire du numéro

Éditeur(s)

Université Sainte-Anne

ISSN

1498-7651 (imprimé)

1916-7334 (numérique)

Découvrir la revue

Citer ce document

Belly, M. \& Magord, A. (2016). Patrimoine oral et valorisation à l'ère du numérique : introduction. Port Acadie, (30), 7-12.

https://doi.org/10.7202/1056917ar d'utilisation que vous pouvez consulter en ligne. 


\title{
Patrimoine oral et valorisation à l'ère du numérique : introduction
}

\author{
Marlène Belly \\ Université de Poitiers \\ André Magord \\ Université de Poitiers
}

Pourquoi étudier aujourd'hui les fonds d'archives orales constitués pour l'essentiel dans les décennies qui ont suivi la Seconde Guerre mondiale ? Sur un plan simple et matériel, que ce soit en France ou en Amérique du Nord francophone, il est urgent de sauvegarder ces fonds souvent préservés sur des supports qui seront sous peu difficilement utilisables. Au-delà de ce souci louable de conservation, un autre élan anime la recherche autour de ce patrimoine, celui de la transmission de savoirs tissés dans des liens serrés entre société, culture et environnement. Ces connaissances, une fois organisées, peuvent ouvrir à une compréhension du monde en cohérence entre ces trois dimensions cruciales de l'existence humaine. Les repères et processus en jeu dans ces articulations entre société et culture font particulièrement défaut dans le monde d'aujourd'hui sous l'influence de la globalisation et de l'hypermédiatisation marchandes. Selon cette orientation de travail qui fut au cœur de la Convention de l'UNESCO (2003) pour la sauvegarde du patrimoine immatériel, le patrimoine culturel immatériel témoigne d'une multitude de savoir-faire et de façons d'être qui, face aux préoccupations actuelles (cohésion sociale, préoccupations environnementales...) peuvent être un levier fondamental au développement aussi bien de l'individu que des 
groupes etle fermentindispensable à l'épanouissement de nouvelles formes d'expression. Dans le contexte de ces perspectives de travail actualisées, l'étude du patrimoine oral immatériel peut devenir un facteur d'ancrage au territoire et un outil de développement culturel, social et économique durable.

Les textes présentés dans ce numéro double de la revue Port Acadie s'inscrivent ainsi dans le renouveau des études scientifiques à partir de fonds documentaires spécifiques - archives sonores et les supports écrits et visuels qui leur sont associés -, de corpus linguistiques, de collections. Ce renouveau s'appuie sur des techniques de numérisation de plus en plus avancées, sur des méthodes de valorisation qui rejoignent des domaines d'application dans les secteurs de la patrimonialisation, du tourisme, de la création artistique et de la participation des populations locales par la mise en place de plateformes collaboratives.

L'originalité des recherches présentées tient au fait qu'elles se situent dans le contexte de la francophonie internationale et des liens spécifiques développés entre le Grand Ouest de la France et la francophonie nord-américaine. L'étude des transferts culturels peut ainsi permettre des éclairages inédits sur le fonctionnement des cultures en mouvement, notamment en contexte diasporique.

En Amérique du Nord, une culture populaire riche a suivi l'immigration puis les migrations de francophones et s'est implantée dans toutes les provinces et territoires canadiens et dans de très nombreuses régions aux États-Unis. Cette culture a accompagné et a été partie prenante des multiples établissements, enracinements et développements francophones dans un milieu où l'anglophonie est devenue de plus en plus majoritaire.

En France, la région Poitou-Charentes a cette spécificité d'être à la fois terre d'émigration vers le Nouveau Monde et aussi terre « de retour en exil » pour les Acadiens déportés entre 1755 et 1763. La notion de patrimoine identitaire ajoute une réflexion problématique sur des faits, des processus, des dynamiques souvent insoupçonnées. Le phénomène des circulations transatlantiques lié au fait acadien s'étale sur plus de quatre siècles d'histoire. Il 
commence au début du XVII ${ }^{\mathrm{e}}$ siècle par une émigration de différents groupes de Français vers le Nouveau Monde. Il est ensuite d'ordre géopolitique puisqu'une partie des descendants de ces colons pionniers acadiens est déportée, entre 1755 et 1763, vers différentes régions du monde, la France entre autres, Belle-Île et Archigny en Poitou en particuliers. Parmi ces Acadiens, une majorité décidera toutefois de repartir vers le Nouveau Monde, la Louisiane surtout, où ils pourront retrouver une liberté qui leur fait défaut, malgré le statut singulier qui leur est accordé dans une France encore monarchique. Ces pérégrinations multiples et dramatiques seront le ferment d'une mémoire qui va traverser les époques et marquer les cultures.

Aujourd'hui les notions de terre d'origine, terre d'accueil, d'exil, de dispersion, de ré-enracinement font de cette tranche d'histoire un phénomène singulier auquel la région du Poitou est fortement reliée. Le fait acadien en Poitou concentre les regards croisés, d'une part, des universitaires autour des thèmes de la mémoire et de l'identité et, d'autre part, du monde associatif pour des raisons de descendance et de préservation patrimoniale et d'amitié entre les peuples. À cette dynamique s'ajoute l'action des pouvoirs publics qui visent à développer le tourisme culturel, les relations internationales et économiques, en s'appuyant sur l'identité historique et patrimoniale singulière de leur territoire.

Le rapport entre un patrimoine matériel et immatériel établi au gré des circulations transatlantiques et un processus identitaire soutenu par les trois vecteurs pré-cités (université, monde associatif, collectivités territoriales) est donc riche et alimenté par des dynamiques d'ordre clairement objectif ainsi que d'ordre subjectif, moins facilement perceptibles.

Comme en France, suite à la Seconde Guerre mondiale et dans les années 1960 et 1970 en particulier, de grandes collectes ethnographiques ont eu lieu auprès de nombreux porteurs de ces courants culturels en Amérique du Nord francophone. Dans la dernière décennie $\mathrm{du} \mathrm{xx}^{\mathrm{e}}$ siècle, différentes tentatives de mise en lien entre certains de ces fonds et la vague des 
humanités numériques n'ont pas pleinement abouti. Dans un monde aujourd'hui hyperconnecté, un projet de valorisation et d'actualisation de ces fonds ne peut être isolé, marginal. Nous sommes en ce sens convaincus que le travail en réseau qui se met en place et qui devrait aboutir à une collection internationale rassemblée et valorisée en commun portera ses fruits.

La thèse de doctorat récemment soutenue par Nathan Rabalais ${ }^{1}$ montre la grande richesse et la possibilité d'un fil conducteur comparatif entre les différents territoires où ont circulé et où continuent de s'échanger ces cultures orales francophones. En étudiant le conte de Jean le Sot en Poitou, en Acadie et surtout en Louisiane, il a ainsi pu retracer un parcours historicoethnographique et géoculturel très novateur et qui ouvrent des pistes de travail propres à une base de données collaborative.

Ce numéro double dans son ensemble porte sur la sauvegarde et la valorisation patrimoniale. Il vise à prolonger d'une part l'étude du rôle social de la culture et, d'autre part, l'interrogation sur l'apport des humanités numériques dans le but d'œuvrer à une réactualisation, réappropriation d'éléments patrimoniaux dans un contexte régional et international de fortes mutations.

La plupart des travaux présentés dans ces dossiers s'inscrivent dans la continuité d'une coopération scientifique sur le long terme entre l’Université de Poitiers et plusieurs universités canadiennes francophones et louisianaises.

Adossée à la mise en place d'une base de données numériques commune, cette coopération scientifique internationale au sein d'un réseau en cours de formalisation s'appuiera sur l'usage du numérique dans le cadre des recherches en sciences sociales. Elle permettra une conjugaison des modes et politiques de valorisation concernant un ensemble culturel cohérent.

Le premier axe d'analyse porte sur les rapports entre patrimoine oral et société.

1 Nathan Rabalais, «Contes rendus: Sources and Development of Louisiana's French and Creole Oral Tradition », thèse de doctorat, Université de Poitiers/Université Tulane, 2015, $238 \mathrm{p}$. 
Lucie Hotte propose en ce sens une piste de réflexion sur les rapports entre la conservation et la valorisation du patrimoine culturel d'une part et la préservation de la mémoire collective en contexte francophone minoritaire d'autre part. Bernard Cherubini s'appuie sur une ethnologie historique centrée sur les migrations transatlantiques et sur une anthropologie du tourisme axée sur les lieux de mémoire afin de réévaluer la place de l'Aquitaine dans le tourisme de mémoire transatlantique (France, Acadie, Québec).

Le chapitre numérique et valorisation du patrimoine oral explore la mise en relation de fonds similaires déposés dans les Universités de France, du Canada francophone et de Louisiane, dans un fonctionnement en réseau des données et des travaux de recherche propres à un fonds historique et interculturel cohérent.

Patricia Heiniger-Castéret et Mathilde Lamothe proposent une étude comparative des méthodes de travail sur les inventaires du patrimoine culturel immatériel dans le contexte du passage au numérique, entre le Québec et la France. Martine Sin BlimaBarru et Pascal Riviale mettent en lumière le contexte dans lequel des campagnes de numérisation ont offert pour la première fois des possibilités d'accès aux fonds du Musée national des Arts et Traditions Populaires à tous les publics, ouvrant ainsi de nouvelles perspectives de recherches et de valorisation. Dans le cadre du projet I-Treasures qui vise à développer une plate-forme ouverte et extensible afin de fournir un accès aux ressources du patrimoine culturel immatériel, de permettre l'échange de connaissances entre chercheurs et de contribuer à la transmission des savoirfaire rares des trésors humains vivants, Catherine Hergott aborde tout particulièrement les technologies permettant de sauvegarder et de transmettre le chant polyphonique corse. Dans le contexte de travaux scientifiques sur le patrimoine culturel immatériel, Pierre-Don Giancarli s'interroge sur l'étape de la transcription dans la constitution du corpus oral. Cette dernière n'est pas sans conséquence sur le travail interprétatif du chercheur.

L'originalité et la richesse de la réflexion portée sur le patrimoine oral francophone tient au fait qu'il est constitué à partir 
de cultures orales en mouvement. Nathan Rabalais suit avec précision les adaptations du conte de Jean le Sot au fil du temps dans la francophonie, en partant du Poitou, en passant par l'Acadie pour arriver en Louisiane où ont également transité des versions en provenance des Caraïbes. L'article de Jean-Pierre Pichette apporte un éclairage sur la diffusion du patrimoine oral des Français d'Amérique et sur l'origine plurielle de ces traditions dont il explique le maintien plus dynamique dans des marges propres à la culture minoritaire.

Le travail scientifique sur le patrimoine oral dans une perspective actualisée ouvre la recherche à des approches pluridisciplinaires qui convergent vers l'objectif commun de valorisation du patrimoine culturel immatériel. L'historien Gregory Kennedy montre ainsi comment s'appuyer sur l'histoire orale afin de porter un éclairage sur un pan peu connu de l'histoire acadienne. Carol Jean Léonard souligne l'intérêt de l'étude de la littérature culturelle toponymique chez les francophones de l'ouest canadien. Il soulève la question épistémologique de la prise en compte de l'affect dans la diffusion de cette toponymie. Corina Crainic analyse avec finesse le rapport entre narration et imaginaire propre à la culture orale en insistant sur le rôle potentiel de l'imaginaire dans la tentative de réappropriation identitaire, voire territoriale au sein de groupes de population minoritaires spoliés dans les Antilles où en Acadie. C'est également le rôle de l'imaginaire que Sérgio Israel Levemfous propose de mettre en lumière en tant qu'élément clé pouvant permettre à des personnages migrants de se réinventer dans un contexte américain. Situées entre réel et fiction, les quêtes d'identité narrées renvoient à la problématique de la réappropriation dans l'étude des cultures orales en mouvement. 